\title{
ON THE MEAN SIZE OF LAND UNITS
}

Siim Maasikamae ${ }^{1}$, Ph.D.

${ }^{1}$ Estonian University of Life Sciences

\begin{abstract}
The size of farms, fields, cadastral parcels and other territories (generally land units) is a common indicator to describe them. The mean size of land units is used for different purposes, for example for comparison of different regions. However, the same mean size of land units can be the result of different initial data. The mean size of two land units is 10 hectares in both cases: $19+1$ hectare or $11+9$ hectare. The disadvantages of mean size are criticised also in literature. In this paper, the area weighted mean size as indicator to describe the holdings land use conditions are presented. The study aim is to show the difference between mean size and area weighted mean size of land units of the holdings The difference between mean size and area weighted mean size of land units is shown on the basis of formal calculations. Then the difference between mean size and area weighted mean size of land units is analysed by empirical data. The formal calculations showed that the difference between mean size and area weighted mean size of land units of the holding depends on the variability of land units' size. The results of the empirical study showed that mean size and area weighted mean size of land units for one holding can differ more than three times while in some cases this difference is small. Finally, the recommendation to use the area weighted mean size for characterisation of land use conditions of land holdings has been made.
\end{abstract}

Key words: area weighted mean area, land holdings, land use conditions.

JEL code: Q10, R59

\section{Introduction}

The size of farms, stock companies and other producers of agricultural products is one of the indicators to describe them. However, the size of agricultural producers can be understood differently. For example, the land area (hectares) and the economic size (expressed in euro) of farms is used in FADN farm return reports (FADN, 2017). J. Yee and M. C. Ahearn (2005:2231) pointed out five different farm size measures: "acres operated per farm, real land and building value per farm, real cash receipts per farm, real cash receipts plus government payments per farm, and an imputed measure of the real capital service flow per farm". The focus of the present study is on the land area as the indicator describing land use conditions of the agricultural producers and size is understood as spatial extent of some part of land, for example the area of cadastral parcel or arable land field. It should be mentioned also that the size of plots is among the indicators describing their spatial properties. Area of plots is used in several studies, for example Neuwirth et al. (2016) and Sikk and Maasikamae (2015a), to describe the study objects and land use conditions.

All kind of agricultural producers (farms, stock companies etc.) are called generally as holdings in the following text if there is no need to point out some specific type of entities. The general term for all kind of plots, for example cadastral parcels or arable land fields, in the following text are called land unit if there is no need to point out some specific type of plots. The combination of plots can be also treated as land units, for example one property can consist of a set of cadastral parcels. Such a set sometimes makes a whole and can be treated as one land unit.

The size of holdings can be researched from different aspects. K. Deininger and D. Byerlee (2012) investigated the balance between small and large farms. The land unit size is the primary characteristic to describe the land use conditions of agricultural holdings (Sikk and Maasikamae, 2015b). Dimitreu et al. (2013) and Terry van Dijk (2003) used the size of land units (parcels) as one of the indicators for characterisation of land fragmentation. Those were just a few examples.

${ }^{1}$ Corresponding author Siim Maasikamäe, e-mail: siim.maasiamae@emu.ee 
However, there is often the need to know some average figures about land units and mean area is one of them. The mean size of land units can also be used for comparison of land use patterns in different regions. For example, Burton and King (1982) used average area per plot and average area per holding for analysing and characterising land consolidation issues. Average farm size is used for international comparison of holdings (Lowder et al., 2016). The mean size of arable land fields inside a plot can be used as the indicator for evaluation of the internal fragmentation of parcels (Aasmae and Maasikamae, 2015). The mean size of land holdings is a usual indicator in several statistical databases, for example European Commission Eurostat database (http://ec.europa.eu/eurostat/data/database) and Statistics Estonia (https://www.stat.ee/). Different statistical publications (Agricultural ...2012; Eurostat regional 2013) provided also average data about agricultural holdings.

Nevertheless, it is necessary to say that mean size of land units as indicator to describe land holdings has some disadvantages. The problem is that the mean size of land units does not say anything about the distribution of those units by their size. The average farm size as indicator is criticised by Bokusheva and Kimura (2016), Demetriou et al. (2013), Lund and Price (1998). It is proposed to use the hectare weighted median as indicator to characterise the degree of land use concentration (MacDonald et al., 2013). The issues of land use concentration are well investigated by Bokusheva and Kimura (2016).

However, the area weighted median size of land units is not a good indicator to describe the land use conditions of a particular landholding. It can be very confusing to use any kind of median (area weighted or simple) for characterising the average land use conditions of a particular holding from a land cultivation point of view. That problem becomes complicated if the number of land units in the land holding is small, sometimes less than 10, and the size of land units is very different. In this light, one can ask, if the mean size and the area weighted mean size are different, and if they are different then how big is this difference?

In the study, the formal calculations of mean size of holdings and the area weighted mean size of holdings are first presented. Then the results of the empirical study are presented. The aim of the paper is to test if the mean size of land units of a holding and area weighted mean size of the same holding can differ remarkably. The first research task was to perform the formal calculations of mean size and area weighted mean size of land units for the abstract holdings. The second task was the calculation of mean size and area weighted mean size of land units of holdings on the basis of empirical data. Final task was the analysis of the results of performed calculations.

\section{Methods and materials}

Two methodical approaches and tasks have been used in the study. Some formal calculations in two versions have been performed at first. It is supposed that there are holdings consisting a large unit and small unit(s). The size of small unit(s) was/were increased step by step till all land units of the holding became equal. The total size of holdings was 60 hectares in both cases.

The initial composition of the holding was $59+1$ hectares according to first version of formal calculations. On the next step the composition of the holding was $58+2$ hectares. The similar changes (decrease of large unit and increase of small unit) continued till there was two equal units of 30 hectares both.

The initial situation of the holding was different in the second version of formal calculations. The number of land units was six (one large and five small units) and the initial composition of the 
holding was $55+1+1+1+1+1$ hectares. On the next step the composition of the holding was $50+2+2+2+2+2$ hectares. The similar changes (decrease of large unit and increase of small unit) continued till there was six equal units of 10 hectares each.

For each step of the area changes the simple mean size of the land units and the area weighted mean size was calculated. The Equation 1 was used for calculation of the simple mean size of land units and the Equation 2 was used for calculation of the area weighted mean size of land units.

$$
\begin{gathered}
\bar{a}=\frac{\sum a_{i}}{\sum n} \\
\bar{a}=\frac{\sum a_{i} w_{i}}{\sum w_{i}}
\end{gathered}
$$

Where:

$\bar{a}$ is the mean area or area weighted mean area of land units;

$a_{i}$ is the area of $i$-th land unit;

$n$ is the number of land units in holding;

$w_{i}$ is the weight of the area of $i$-th land unit (in this case the area of land unit is the weight for itself).

The corresponding graphs were composed to illustrate the changes of the area weighted mean size if the relative importance of small land units in the holding increases.

Secondly, two visual comparisons of the mean size and area weighted mean size of holdings were performed on the basis of empirical observations. The Tartu County in Estonia was the study area for the mentioned comparisons. The first comparison of the mean size and area weighted mean size was made for the agriculture and forest properties consisting of more than one cadastral parcel. There is no distinction between agriculture and forest properties in Estonian cadastre and the common name of the intended use for such parcels is profit yield land. Data about cadastral parcels were provided by the Estonian Land Board (dated as of 1.01.2017).

The second comparison of the mean size and area weighted mean size was made for the arable land fields of holdings applying for the different subsidies from the Agricultural Registers and Information Board (ARIB hereinafter). Data about arable land fields were from the ARIB fields registers (in ESRI shape format.) One agricultural holding uses more than one arable land field as a rule. Some holdings are large and used hundreds of arable land fields as separate land units.

The Equation 1 and Equation 2 were used for the calculation of the mean size and area weighted mean size for the mentioned above two comparisons. The $X-Y$ scatter plots were used for visual comparison of mean size and area weighted mean size of holdings. The holdings were ordered increasingly by their simple mean size. In this way dots representing the mean size of observed holdings made a line on the chart. The area weighted mean size of the same holdings were presented also on the same chart. In some case the mean size and the area weighted mean size are similar (the respective dots on the chart are close to each other) while in some cases the difference between mean size and area weighted mean size is bigger.

Finally, the general comparison of the mean size of land units and the area weighted mean size was made. 


\section{Research results and discussion}

The Figure 1 and Figure 2 showed the results of the formal calculations, described on the part of methods and materials. The figures show the change of the mean area of land unit depending on the ratio of small and large land units in the holding. The Figure 1 shows the changes of the weighted mean size for the land holding consisting of two land units and Figure 2 respectively for the holding consisting six land units. The total area of the holding is 60 hectares in both cases.

Source: author's calculations

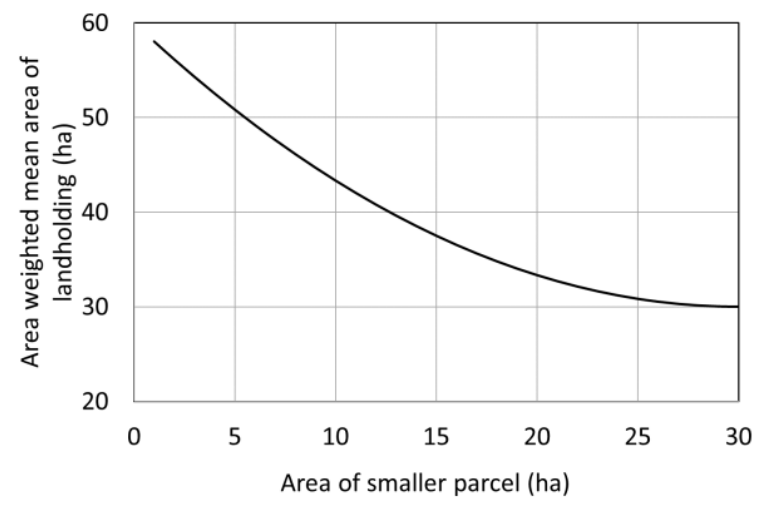

Fig. 1. The weighted mean area of the land units depending on the ratio of small and large land unit (case of one small and one large land unit)

If the size of smaller land unit changes from one hectare to 30 hectares (Fig. 1) then the area weighted mean size changes from the 58.03 hectares to 30 hectares while the mean size of two land units is all the time 30 hectare.

Source: author's calculations

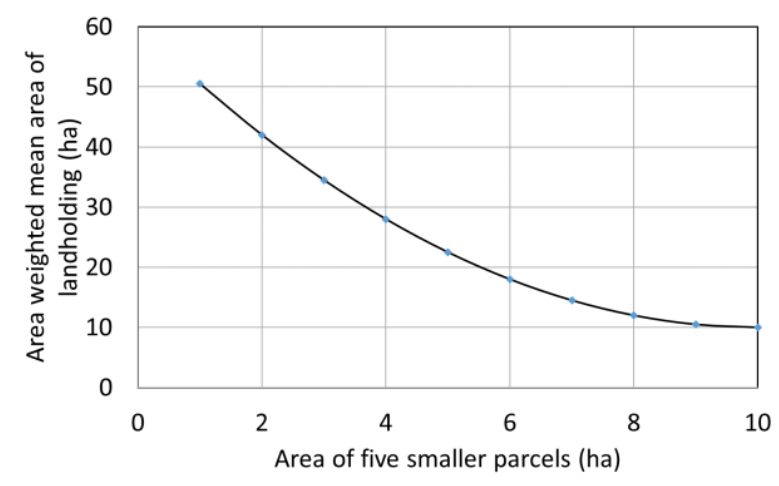

Fig. 2. The weighted mean area of the land units depending on the ratio of small and large land units (case of five small and one large land units)

The curve on the Figure 2 shows the change of the area weighted mean size for the holding consisting one large land unit and five small land units. The initial value of the area weighted mean size for the six land units $(55+1+1+1+1+1$ hectares) is 50.5 hectares and it will be 10 hectares when all six land units will be equal by size. The simple mean size of the holding is 10 hectares all the time, not depending on the proportions of land units in the holding.

The formal calculations illustrate the fact that mean size and area weighted mean size can differ remarkably, from 1.9 to 5 times in presented calculations. The comparisons of the actual differences between mean size and area weighted mean size are presented on the figure 3, Figure 4, Figure 5 and Figure 6. There are two markers for each holding on those figures, dark points to indicate the mean size of the land holdings and grey diamonds to indicate the area weighted mean size respectively. All observations (holdings) were ordered by their mean size when 
the graphs were constructed. It was necessary in order to make a clear distinction between two types of markers. Figure 3, Figure 4 and Figure 5 show the difference between mean size and area weighted mean size for the agriculture and forest properties consisting of at least two cadastral parcels. Three figures were used to describe the same phenomenon in order to reduce the overlap of markers on the chart and to get better visual readability.

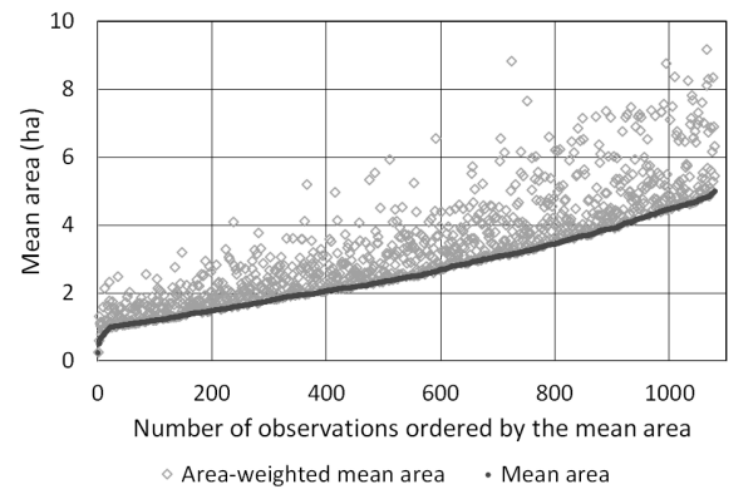

Source: author's calculations based on Estonian Land Board data

Fig. 3. Comparison of the mean area and area weighted mean area of parcels of the profit yield land properties (the total of properties in the group is $2-10 \mathrm{ha}, \mathrm{N}=1080$ )

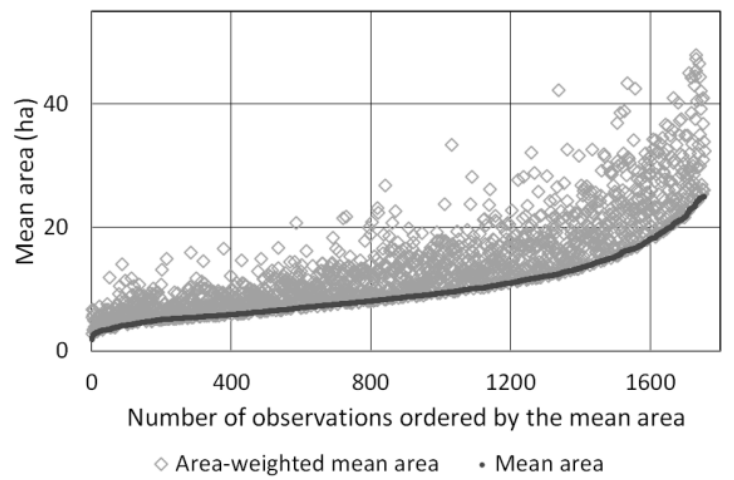

Source: author's calculations based on Estonian Land Board data

Fig. 4. Comparison of the mean area and area weighted mean area of parcels of the profit yield land properties (the total of properties in the group is $10-50$ ha, $\mathbf{N}=1755$ )

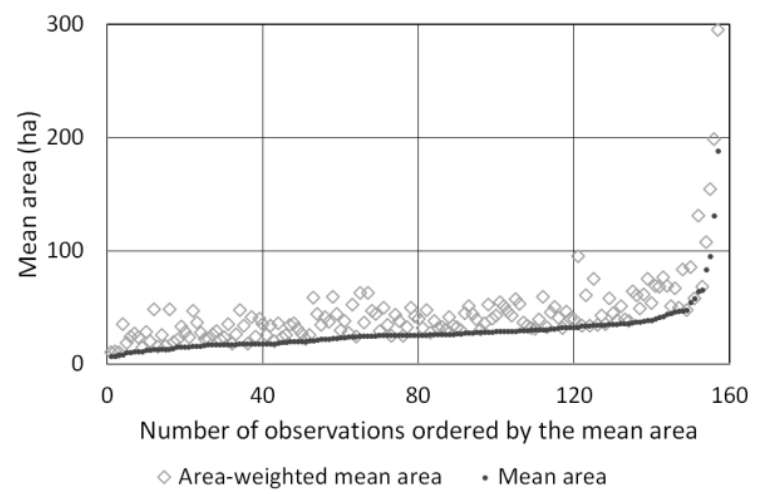

Source: author's calculations based on Estonian Land Board data

Fig. 5. Comparison of the mean area and area weighted mean area of parcels of the profit yield land properties (the size of properties in the group is more than 50 ha, $N=157$ )

The visual assessment of the Figure 3, Figure 4 and Figure 5 showed that for some holdings the mean size and area weighted mean size are similar while in some cases there are big differences between those indicators. The Figure 6 shows the comparison of mean size and area weighted 
mean size for arable land fields by land holdings applying for subsidies from ARIB. This figure is similar to the figures describing differences between mean size and area weighted mean size for the agriculture and forest properties. For some holdings the field mean size and area weighted mean size are similar while in some cases the differences are more than two times.

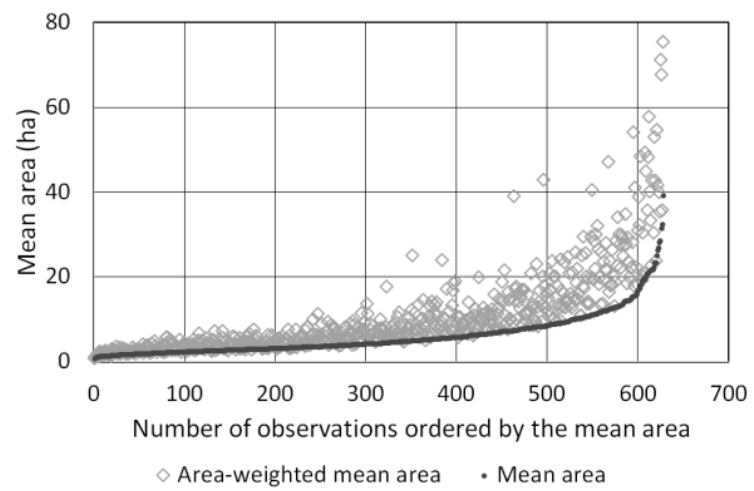

Source: author's calculations based on the Estonian Agricultural Registers and Information Board data

Fig. 6. Comparison of the mean area and area weighted mean area of the arable land fields of agricultural holdings

The Table 1 gives some numerical insights into the differences between mean size and area weighted mean size for the agriculture and forest properties. The properties are divided into three groups and this division corresponds to the Figure 3, Figure 4 and Figure 5.

Table 1

The comparison of the mean area of parcels and the area weighted mean area of parcels of the agricultural and forest (profit yielding land) properties

\begin{tabular}{|c|c|c|c|c|c|c|c|}
\hline \multirow{2}{*}{$\begin{array}{c}\text { Area of } \\
\text { properties } \\
\text { (ha) }\end{array}$} & \multirow{2}{*}{$\begin{array}{c}\text { Number } \\
\text { of } \\
\text { properties }\end{array}$} & \multirow{2}{*}{$\begin{array}{c}\text { Number } \\
\text { of } \\
\text { parcels }\end{array}$} & \multicolumn{2}{|c|}{$\begin{array}{l}\text { Total area of fields in } \\
\text { the group }\end{array}$} & \multicolumn{2}{|c|}{$\begin{array}{c}\text { Mean area of parcels } \\
\text { (ha) }\end{array}$} & \multirow{2}{*}{$\begin{array}{c}\text { Area- } \\
\text { weighted } \\
\text { mean and } \\
\text { simple } \\
\text { mean ratio }\end{array}$} \\
\hline & & & ha & percentage & $\begin{array}{l}\text { simple } \\
\text { mean }\end{array}$ & $\begin{array}{c}\text { area- } \\
\text { weighted } \\
\text { mean }\end{array}$ & \\
\hline 2.0 to 10.0 & 1080 & 2388 & 6088 & 10.3 & 2.5 & 3.8 & 1.52 \\
\hline 10.1 to 50.0 & 1755 & 4476 & 41164 & 69.9 & 9.2 & 16.6 & 1.80 \\
\hline $\begin{array}{l}\text { More than } \\
50.0\end{array}$ & 157 & 462 & 11661 & 19.8 & 25.2 & 63.7 & 2.53 \\
\hline Total & 2992 & 7326 & 58913 & 100.0 & 8.0 & 24.6 & 3.07 \\
\hline
\end{tabular}

Source: author's calculations based on Estonian Land Board cadastral data

The figures in the Table 1 show that on average the mean size and area weighted mean size of properties differ about 3 times. However, the difference between mean size and area weighted mean size exists in all area groups of properties. The similar calculations were made for the arable land fields in the holdings. Results of those calculations are presented in Table 2. 
The comparison of the mean area of arable land fields and the area weighted mean area of arable land fields of agricultural holdings

\begin{tabular}{|c|c|c|c|c|c|c|c|}
\hline \multirow{2}{*}{$\begin{array}{l}\text { Number of } \\
\text { fields in } \\
\text { land } \\
\text { holding }\end{array}$} & \multirow{2}{*}{$\begin{array}{c}\text { Number } \\
\text { of investi- } \\
\text { gated } \\
\text { land } \\
\text { holdings }\end{array}$} & \multirow{2}{*}{$\begin{array}{c}\text { Number } \\
\text { of investi- } \\
\text { gated } \\
\text { arable } \\
\text { land fields }\end{array}$} & \multicolumn{2}{|c|}{$\begin{array}{l}\text { Total area of fields in } \\
\text { the group }\end{array}$} & \multicolumn{2}{|c|}{ Mean of fields (ha) } & \multirow{2}{*}{$\begin{array}{c}\text { Area- } \\
\text { weighted } \\
\text { mean and } \\
\text { simple } \\
\text { mean } \\
\text { ratio }\end{array}$} \\
\hline & & & ha & percentage & $\begin{array}{l}\text { simple } \\
\text { mean }\end{array}$ & $\begin{array}{l}\text { area- } \\
\text { weighted } \\
\text { mean }\end{array}$ & \\
\hline 2 to 5 & 544 & 1633 & 6185 & 10.0 & 3.8 & 12.2 & 3.21 \\
\hline 6 to 10 & 128 & 941 & 5438 & 8.8 & 5.8 & 18.4 & 3.17 \\
\hline $\begin{array}{l}\text { More than } \\
10\end{array}$ & 147 & 4791 & 50263 & 81.2 & 10.5 & 29.7 & 2.83 \\
\hline Total & 819 & 7365 & 61886 & 100.0 & 8.4 & 26.9 & 3.20 \\
\hline
\end{tabular}

Source: author's calculations based on Estonian Agricultural Registers and Information Board data

As with the agriculture and forest properties, the mean size and area weighted mean size of the arable land fields of the holdings differs on average 3.2 times. Similar differences can be observed if one looks at the holdings by groups.

The aim of the research was to test if the mean size of land units of a holding and area weighted mean size of the same holding can be different and how big this difference can be. Results of this study showed that the mean size and area weighted mean size of some holdings can be different while for some holdings this difference is practically missing. Such pattern occurred for the parcels of the agricultural and forest (profit yielding land) properties and as well for the arable land fields of agricultural holdings. The difference between mean area and area weighted mean area shows that the holding consists of land units that are different by size. The mean area and area weighted mean area are similar if the area of land units is similar. Thus, the comparison of the mean area and area weighted mean area gives additional information about the distribution of land units by size in land holdings.

It is important to keep in mind the purpose for which the mean size of land holdings is used. It can be used for assessment of the land use conditions (spatial properties) of particular holdings but can also be used for example for comparison of the general land use parameters of different regions. Thus, the clear distinction must be made if the area weighted mean size is used for characterisation land use conditions of particular holdings (holdings level) or for the description of general holdings structure in particular region. The area weighted mean size does not substitute the mean size of land units in all cases. They rather complement each other.

In some aspects, the size of the land unit is a value itself, especially if use of arable land is discussed. The possibilities to combine the different land cultivation activities on the large fields are more flexible than on the small ones. Some very small land units of the holding can reduce the mean size of the land units while most of the land cultivation activities occur on the large land units. In this way, the actual land use conditions and the mean size of land units are not well correlated. The use of the area weighted mean size of land units instead of simple mean size is a possibility to solve this problem.

The presented results in this paper have a preliminary character. There are several questions for the further research. An important issue for the further studies is the place and role of mean size of land units among other indicators describing spatial properties of holdings, e.g. land fragmentation. 


\section{Conclusions, proposals, recommendations}

1) The use of area weighted mean size of land units instead of simple mean size applies to the purpose if we want to characterise the land use conditions of particular holding consisting of several land units and the size of those units is very different.

2) The results of the study showed that in average the mean area and area weighted mean area of land units differ about two-three times.

3) The formal calculations showed that the difference between mean size and area weighted mean size is the bigger if the variability among land units of one holding is bigger.

4) The area weighted mean size of land units can be used first of all for the characterisation of spatial properties and land use conditions of holdings.

\section{Bibliography}

1. Aasmae, K., Maasikamae, S. (2014). Internal Fragmentation of Agricultural Parcels. Research for Rural Development 2014, 2: Annual 20th International Scientific Conference Proceedings. Jelgava, pp. $278-282$.

2. Agricultural Census 2010. (2012). Eesti Statistika, Statistics Estonia, p 96. Retrieved: https://www.stat.ee/valjaanne-2012_pollumajandusloendus-2010. Access: 15.01.2018.

3. Bokusheva, R. and Kimura, S. (2016). Cross-Country Comparison of Farm Size Distribution. OECD Food, Agriculture and Fisheries Papers, No. 94, OECD Publishing, Paris, p. 46. Retrieved: http://dx.doi.org/10.1787/5jlv81sclr35-en. Access 15.01.2018.

4. Burton, S., King, R. (1982) Land Fragmentation and Consolidation in Cyprus: A Descriptive Evaluation. Agricultural Administration, Volume 11, Issue 3, pp 183-200.

5. Deininger, K. and Byerlee, D. (2012). The Rise of Large Farms in Land Abundant Countries: Do They Have a Future? World Development, Volume 40, No. 4, pp. 701-714.

6. Demetriou D., Stillwell J., See L. (2013) A New Model for Measuring Land Fragmentation. Computers, Environment and Urban Systems, Volume 39, pp. 71-80.

7. Eurostat regional yearbook 2013. (2013). European Commission, 276 pp. Retrieved: http://ec.europa.eu/eurostat/documents/3217494/5784301/KS-HA-13-001-EN.PDF. Access: 17.01.2018.

8. FADN (2017). Pollumajandustootjate majandusnaitajad / FADN Farm Return 2016. Maamajanduse Infokeskus, Retrieved: http://www.maainfo.ee/data/trykis/aastaraamat/FADN2016.pdf. Access: 15.01.2018.

9. Lowder, S. K., Skoet, J., Raney, T. (2016). The Number, Size, and Distribution of Farms, Smallholder Farms, and Family Farms Worldwide. World Development, Volum 87, pp. 16-29.

10. Lund, P. and Price, R. (1998). The Measurement of Average Farm Size. Journal of Agricultural Economics, Volum 49, pp. 100-110.

11. MacDonald, J.M., Korb, P. and Hoppe, R. A. (2013). Farm Size and the Organization of U.S. Crop Farming, ERR-152. U.S. Department of Agriculture, Economic Research Service. Retrieved: https://www.ers.usda.gov/webdocs/publications/45108/39359_err152.pdf. Access: 9.01.2018.

12. Neuwirth, C., Hofer, B., Schaumberger, A. (2016) Object view in spatial system dynamics: a grassland farming example. Journal of Spatial Science, Volun 61, No. 2, pp. 367-388.

13. Pollumajandusloendus. 2010. Agricultural Census. (2012). Eesti Statistika, Statistics Estonia, p 96. Retrieved: https://www.stat.ee/valjaanne-2012_pollumajandusloendus-2010. Access: 15.01.2018.

14. Sikk, K., Maasikamae, S. (2015a) Spatial properties of large agricultural landholdings of Estonia. In: Integrated and Sustainable Regional Development, 38: International Conference "Economic Science for Rural Development", Jelgava, 23 - 24 April 2015. Jelgava, pp. 39-49.

15. Sikk, K., Maasikamae, S. (2015b) Impact of agricultural landholding size on the land fragmentation. In: Annual 21st International Scientific Conference:" Research for Rural Development" Volume 2, Jelgava, Latvia, 13-15 May 2015, pp. 301-306.

16. Van Dijk, T. (2003). Scenarios of Central European land fragmentation. Land Use Policy 20, pp. 149-158

17. Yee, J. and Ahearn, M. C. (2005). Government policies and farm size: does the size concept matter? Applied Economics, Volume 37, Issue 19, pp. 2231-2238. 